\title{
Modulation of protein $S$ and growth arrest specific 6 protein signaling inhibits pancreatic cancer cell survival and proliferation
}

\author{
VIJAYA S. PILLI $^{1 *}$, ARANI DATTA ${ }^{1 *}$, ADRIANNE DORSEY ${ }^{1}$, BO LIU $^{2}$ and RINKU MAJUMDER ${ }^{1}$ \\ ${ }^{1}$ Department of Biochemistry, Louisiana State University Health Sciences Center, New Orleans, LA 70112; \\ ${ }^{2}$ Department of Surgery, University of Wisconsin, Madison, WI 53705, USA
}

Received May 24, 2018; Accepted May 8, 2020

DOI: $10.3892 /$ or.2020.7689

\begin{abstract}
Thrombotic complications and hypercoagulopathies are commonly associated with the progression of pancreatic ductal adenocarcinoma (PDAC). Although the mechanistic link between the two phenomena is uncertain, there is evidently an increase in procoagulant proteins and a decrease in anticoagulants in PDAC patients. For example, the anticoagulant protein S (PS) is decreased during the progression of PDAC, a condition that possibly contributes to the hypercoagulopathies. PS is also an important signaling molecule that binds a family of tyrosine kinase receptors known as TAM (Tyro3, Axl and Mer) receptors; TAM receptors are often upregulated in different cancers. Growth Arrest Specific 6 or GAS6 protein, a homolog of PS, is also a TAM receptor family ligand. The downstream signaling pathways triggered by this ligand-receptor interaction perform diverse functions, such as cell survival, proliferation, efferocytosis, and apoptosis. Targeting the TAM receptors to treat cancer has had limited success; side effects are a significant obstacle due to the widespread numerous functions of TAM receptors. In the present study, it was revealed that PS-TAM interaction was pro-apoptotic, whereas GAS6-mediated TAM signaling promoted proliferation and survival in select PDAC cell lines. Furthermore, by regulating the balance between these two signaling pathways (by overexpressing PS or knocking down GAS6), the proliferative potential of the cells was decreased. Both long-term and short-term effects of natural PS
\end{abstract}

Correspondence to: Dr Rinku Majumder, Department of Biochemistry, Louisiana State University Health Sciences Center, 1901 Perdido St., Medical Education Building, Room 7114, New Orleans, LA 70112, USA

E-mail: rmajum@lsuhsc.edu

${ }^{*}$ Contributed equally

Abbreviations: PS, protein S; GAS6, growth arrest specific protein 6; PDAC, pancreatic ductal adenocarcinoma; TAM, Tyro3, Axl and Mer

Key words: Protein S, GAS6, TAM receptor, pancreatic cancer, UNC2025 overexpression were comparable to the treatment of the cells with the drug UNC2025, which inhibits the Mer-receptor. The present study lays the foundation for investigation of PS as a therapeutic agent to control cancer progression and to concurrently arrest thrombotic events.

\section{Introduction}

Protein S (PS) is a naturally occurring anticoagulant. Primarily produced by the liver, PS circulates in the plasma at a concentration of $350 \mathrm{nM}$ and mediates its anticoagulant function by either direct binding to Factor IXa or as a cofactor of activated protein C (APC) and tissue factor pathway inhibitor (TFPI) (1-3). PS also has a variety of non-anticoagulant functions (4). PS binds and activates a family of receptor tyrosine kinases collectively known as TAM (Tryo3, Axl, and Mer) receptors $(5,6)$. PS-TAM receptor interaction regulates a number of physiological processes, such as cell proliferation, survival, apoptosis, vasculogenesis, and inflammatory cytokine release (7-10).

Growth arrest specific 6 (GAS6) protein is another TAM receptor ligand (5). Heart, lungs, kidneys, endothelial, and muscle cells produce GAS6. Despite the structural homology $(\sim 42 \%)$ shared with PS, GAS6 functions only in activating TAM receptors (11-13). Both PS and GAS6 bind the different TAM receptors with variable affinities (14). GAS6 affinity for the TAMs are Axl > Tyro3 >> Mer; PS activates Mer and Tyro3, although its binding with Axl is still debated (12). Small molecule inhibitors and knockdown of TAM receptors are approaches that have been investigated as therapies to inhibit proliferation of various types of tumors; however, these studies have had limited success in inhibition of proliferation (15). Paradoxically, although TAM receptor inhibition restricts tumor progression, the downstream TAM signaling necessary for phagocytosis and other antitumor effector functions are also inhibited (15-17). Furthermore, because TAM receptors and their ligands are implicated in multiple pathways, therapies that target these receptors must take into account the possibility of adverse responses (14).

Pancreatic ductal adenocarcinoma (PDAC) is estimated to be the fourth most lethal form of cancer in the United States (18). The systemic nature of the disease confers poor prognosis, with an overall median survival of 5-8 months and with $<5 \%$ of patients surviving more than 5 years (19). Cancer 
patients are at an increased risk of venous thromboembolism (VTE), the highest incidence occurring among individuals with pancreatic and brain cancers (20-22). Lindahl et al reported that, during disease progression, patients with pancreatic cancer exhibited a significant decrease in plasma anticoagulants such as antithrombin, protein $\mathrm{C}$, and free PS (23). However, the effect of the decrease in free PS on TAM signaling has not been investigated.

In the present study, the ratio of PS and GAS6 was revealed to be associated to a function of the aggressiveness (time of replication) of the two cell lines, PANC-1 and MIA PaCa-2. MIA PaCa-2 is currently used as an in vitro model of PDAC carcinogenesis (24). We then modulated the PS/GAS6 ratio to confirm that the balance between the two proteins determines the cell survival and proliferation rate. GAS6 overexpression enhanced survival and proliferation of PANC-1 and MIA $\mathrm{PaCa}-2$ cells. Conversely, either overexpression of PS or knocking down of GAS6 inhibited cell proliferation and promoted apoptosis. Notably, the degree of inhibition of proliferation by either PS overexpression or GAS6 knockdown was comparable to that achieved with a Mer-specific inhibitory drug. It was concluded that PS functioned as a natural promoter of apoptosis in pancreatic cancer cells. In addition, the present study demonstrated that increased expression of PS could be a strategy for reducing aggressiveness of PDAC without targeting essential TAM receptor signaling pathways.

\section{Materials and methods}

Cell culture. Human pancreatic cancer cell lines (PANC-1, MIA $\mathrm{PaCa}-2$, and BxPC-3) were obtained from ATCC. PANC-1 cells were grown in high glucose DMEM supplemented with $10 \%$ fetal bovine serum (FBS) (Life Technologies; Thermo Fisher Scientific, Inc.) and (1X) antibiotic-antimycotic solution (Life Technologies; Thermo Fisher Scientific, Inc.) at $37^{\circ} \mathrm{C}$ with $5 \%$ $\mathrm{CO}_{2}$. MIA PaCa-2 received the same complete medium with supplementation of horse serum (Life Technologies; Thermo Fisher Scientific, Inc.) to a final concentration of $2.5 \%$. BxPC-3 cells were grown in RPMI-1640 medium (Life Technologies; Thermo Fisher Scientific, Inc.) supplemented with 10\% FBS and antibiotic-antimycotic solution. These cell lines were selected based on the variations in the cell doubling times which were referred to as the aggressiveness of the cell. MIA PaCa-2 has been revealed to have the shortest doubling time (40 h), PANC-1 a moderate doubling time (52 h) and BxPC-3 the highest doubling time $(72 \mathrm{~h})(25,26)$. BxPC-3 cells were not used in our PS/Gas6 overexpression studies because the cells grow too slowly. We could not use healthy pancreatic duct epithelial cells due to their unavailability. Regarding other non-cancerous control cells, such as H6C7, which are commercially available, since these cell lines are immortalized and their phenotypes are not the same as the primary cells $(27,28)$ they were not used. Instead, respective empty vectors were used as controls since we overexpressed or knocked down the genes in our experiments.

Transfection and lentiviral infection. PANC-1 and MIA $\mathrm{PaCa}-2$ cells were separately seeded in 6-well plates at $1.5 \times 10^{6}$ cells/well and transfected with pcDNA-V5-His containing Pros1 (protein S) insert, a gift from Dr Rezende (29).
The transfection was performed with $4 \mu \mathrm{g}$ of plasmid DNA and Lipofectamine 2000 (Life Technologies; Thermo Fisher Scientific, Inc.) as previously described (30). The cells were subjected to $10 \mu \mathrm{g} / \mathrm{ml}$ Blasticidin (Sigma-Aldrich; Merck $\mathrm{KGaA}$ ) antibiotic selection to obtain stable expression clones. For GAS6 overexpression and knockdown studies, we obtained from Dr Sonja Loges (University Medical Center Hamburg-Eppendorf, Hamburg, Germany) LeGo-iG2-Puro (GFP-expressing) vector containing the GAS6 insert and LeGO-C-Zeo (mCherry expressing) containing shGAS6 insert, which we verified by sequencing prior to use. The production of lentiviral particles and the lentiviral gene transfer into PANC-1 and MIA PaCa-2 cells were performed as outlined by Weber et al (31). For detailed protocols and vector maps, please refer to http://www.lentigo-vectors.de. Generation of virus particles and titration were performed as previously described (32). The GAS6-overexpressing cells were subsequently sorted by FACS analysis for GFP-positive cells and cultured to generate stable cell lines. The cells with GAS6 knocked down were stably selected with $500 \mu \mathrm{g} / \mathrm{ml}$ Zeocin (Thermo Fisher Scientific, Inc.).

$R T-q P C R$ assessment of gene expression. Cells were seeded in 6-well plates at a density of $3 \times 10^{5}$ cells/well. RNA was isolated using RNeasy Plus Mini Kit (Qiagen, Inc.), according to the manufacturer's instructions. The RNA concentration was measured via NanoDrop (Thermo Fisher Scientific, Inc.). Two $\mu \mathrm{g}$ of RNA was used to synthesize cDNA. RT-qPCR was performed with qScript ${ }^{\circledR}$ cDNA Supermix (Quanta BioSciences, Inc.), according to the manufacturer's instructions. The quantification of the genes of interest was performed with PerfecCTa SYBR Green FastMix (Quanta BioSciences, Inc.) according to the manufacturer's instructions. The following primers were used: 5'-TCATGAAGATCCTCACCG AG-3' (forward) and 5'-TT GCCAATGGTGATGACCTG-3' (reverse) for $\beta$-Actin; 5'-ATCAAGGTCAACAGGGATGC-3' (forward) and 5'-CTTCTCCGTTCAGCCAGTTC-3' (reverse) for GAS6; 5'-CCTAGTGCTTCCCGTCTCAG-3' (forward) and 5'-TTTCCGGGTCATTTTCAAAG-3' (reverse) for Pros1; 5'-ACACCCCAGAGGTGCTAATG-3' (forward) and 5'-ACG AGAAGGCAGGAGTTGAA-3' (reverse) for Axl; 5'-TGC CCTGGGAATGGAGTATC-3' (forward) and 5'-A TCTTAG CAATGCGGCCTTG-3' (reverse) for Mertk; 5'-GTGGCT GACTTCGGACTGTC-3' (forward) and 5'-AGCTGTCAT GATCTCCCACA-3' (reverse) for Tyro3. The qPCR conditions included initial denaturation at $95^{\circ} \mathrm{C}$ for $5 \mathrm{~min}$, denaturation at $95^{\circ} \mathrm{C}$ for $15 \mathrm{sec}$ annealing and extension at $60^{\circ} \mathrm{C}$ for $1 \mathrm{~min}$ with 40 cycles. To analyze the expression levels, the average of each sample was used according to its primer and the following calculations were performed to determine the fold change: $\Delta \mathrm{Cq}=($ PROS1-actin $), \Delta \mathrm{Cq}=($ GAS6-actin $) \rightarrow \Delta \Delta \mathrm{Cq}=(\Delta$ $\left.\mathrm{Cq}_{\text {sample }}-\Delta \mathrm{Cq}_{\text {reference }}\right) \rightarrow$ Fold Change $=2^{-\Delta \Delta \mathrm{Cq}}$ (33).

Flow cytometry. PANC-1 and MIA PaCa-2 stable cell lines overexpressing control vector (pCDNA6-V5-His) or PS were produced as aforementioned. These stable cell lines were synchronized by serum starvation for $60 \mathrm{~h}$. After synchronization, the cells were washed with PBS and collected by treatment with Accutase (cat. no. AT-104; Innovative Cell Technologies, Inc.) digestion performed at room temperature for $5 \mathrm{~min}$. 
The Accutase was neutralized by regular growth medium containing 10\% FBS. Cells were stained for Annexin-V and 7AAD using BD Biosciences (cat. no. 559763) and analyzed for Annexin-V and 7AAD binding using FACSCalibur. We were unable to perform flow cytometric experiments with the cells that were transfected with Gas-6-knockdown construct since the constructs contained GFP as internal control.

Protein expression via immunoblotting. PANC-1 and MIA $\mathrm{PaCa}-2$ cells [empty vector (EV) control], PS overexpressing, GAS6 overexpressing and knocked down) were separately plated in 6-well plates at a density of $3 \times 10^{5}$ cells $/ \mathrm{ml}$ and grown for $48 \mathrm{~h}$. The cells were lysed in RIPA buffer $(20 \mathrm{mM}$ Tris-HCl pH 7.5, $150 \mathrm{mM} \mathrm{NaCl}, 1 \mathrm{mM} \mathrm{Na} 2$ EDTA, $1 \mathrm{mM}$ EGTA, 1\% NP-40, $1 \%$ sodium deoxycholate, $2.5 \mathrm{mM} \mathrm{Na}_{4} \mathrm{P}_{2} \mathrm{O}_{7}$, $\left.1 \mathrm{mM} \mathrm{Na} \mathrm{VO}_{4}\right)$, and total lysate protein was assessed by BCA assay (Thermo Fisher Scientific, Inc.). SDS-PAGE (10\%) and immunoblotting were performed with $40 \mu \mathrm{g}$ of protein from each sample. With the exception of sheep PS antibody (dilution 1:1,000; cat. no. PAHPS-S; Haematologic Technologies, LLC), the following primary antibodies used for probing were obtained from Cell Signaling Technology (CST), Inc.: Mouse phospho-p53 antibody (dilution 1:1,000; product no. 9286) and rabbit phospho-HSP27 antibody (dilution 1:1,000; product no. 9709). All blots were normalized with rabbit $\beta$-actin antibody (dilution 1:1,000; product no. 4967S). Blots were incubated with primary antibodies at $4{ }^{\circ} \mathrm{C}$ overnight. After washing, the blots were incubated with the appropriate horseradish peroxidase-conjugated secondary antibody at room temperature for $30 \mathrm{~min}$. The secondary antibodies obtained from Cell Signaling Technology, Inc. were the following: Anti-rabbit IgG, HRP-linked antibody (dilution 1:5,000; product no. 7074) and anti-mouse IgG, HRP-linked antibody (dilution 1:5,000; product no. 7076) was obtained from Cell Signaling Technology, Inc. For PS detection, anti-sheep IgG, HRP-linked secondary antibody (dilution 1:5,000; cat. no. 81-8620) was obtained from Thermo Fisher Scientific, Inc. Images were developed using ECL reagent (cat. no. 32109; Thermo Fisher Scientific, Inc.) with Amersham Imager 600 (GE Healthcare). All immunoblots were repeated thrice, and the band densities were quantitated by ImageJ V1.51 software (National Institutes of Health).

Cell viability assay using MTT dye. Cells were plated in 96-well plates at a density of $5 \times 10^{3}$ cells/well in $90 \mu 1$ of complete medium. After one and five days of incubation, $10 \mu \mathrm{l}$ of $5 \mathrm{mg} / \mathrm{ml}$ MTT (Sigma-Aldrich; Merck KGaA) was added to the cells and further incubated for $4 \mathrm{~h}$. The supernatants were discarded, $100 \mu 1$ of DMSO was added per well, and the crystals were dissolved by agitating for $5 \mathrm{~min}$. The absorbance value was measured by a microplate reader at $570 \mathrm{~nm}$. The relative fold change of absorbance between PS/GAS6-overexpressing cells compared with control cells that contained the empty vector was calculated for the subsequent days, with the day 1 absorbance value as the baseline. At least three independent experiments were performed. For experiments involving drug treatments, UNC2025 (MedChemExpress) was added to cells at variable concentrations alongside a similar volume of vehicle control. Treatment was performed $8 \mathrm{~h}$ after cell seeding and readings were obtained on days 1,3 , and 5 .
Cell proliferation assay using crystal violet. To assess the aggressiveness of single cells with differing genotypes to grow into a colony, PANC-1 and MIA PaCa-2 cells (EV control, PS-overexpressing, GAS6-overexpressing) were plated at a low density $(1,000$ cells/well) in 6 -well plates and allowed to generate single colonies for 14 days. The medium was replenished every three days. The colonies were washed twice in PBS and stained with $0.5 \%(\mathrm{v} / \mathrm{v})$ crystal violet for $20 \mathrm{~min}$ at room temperature as previously described (34). The plates were imaged under white light with Amersham Imager 600 and colonies with a minimum of 50 cells in each, were compared using Clono-Counter software (35).

Statistical analysis. Data from PS, Gas6 or Gas6 shRNA or overexpressing cells were compared against an empty vector or a scramble shRNA vector control. The test group data were analyzed against the control group using one-way ANOVA. A Bonferroni correction was applied to the P-values obtained from ANOVA to control for multiple comparisons, and this was performed separately for each of the two cell lines PANC-1 and MIA PaCa-2. The data for the colony formation, MTT assays were expressed as the mean \pm standard deviation (SD) and error bars in the figures represent the SD. Statistical analysis was performed using GraphPad Prism 7 software (GraphPad Software, Inc.). P-values of $<0.05$ were considered to indicate a statistically significant difference.

\section{Results}

PS/GAS6 ratio is directly associated with the aggressiveness of pancreatic cancer cell lines. Since the selected cell lines were similar in origin, it was investigated whether cell growth rate was related to the basal levels of PS and GAS6. MIA PaCa-2, PANC-1, and BXPC-3 with population doubling times of 40,52 and 72 h respectively (per information from ATCC) were used. The basal levels of the three TAM receptors were relatively uniform among the three cell lines, i.e., less than 5\% difference in the expression level (Fig. 1A). Notably, although PANC-1 cells, with an intermediate degree of aggressiveness, had a PS/GAS6 ratio of 1, MIA PaCa-2 cells had a significantly lower PS/GAS6 ratio (2.183:5.588) (indicating that the most aggressive cell line had more Gas6) and BXPC-3 cells, the least aggressive cell line, had a markedly higher PS/GAS6 ratio (12.817:2.151) (Fig. 1B). These data associated the degree of aggressiveness of the cell lines to the PS/GAS6 ratio, and the data revealed that a lower PS/GAS6 ratio was associated with increased proliferative potential, whereas a higher ratio was associated with decreased proliferative ability.

$P S$ overexpression reduces the survival and proliferation of PANC-1 and MIA PaCa-2 cells. Since the relative levels of PS and GAS6 were associated with the aggressiveness of pancreatic cancer cell lines, the PS/GAS6 ratios were altered to confirm their importance in determining proliferative potential. The expression of apoptotic/survival markers of PANC-1 and MIA PaCa-2 cells stably overexpressing PS was first assessed by immunoblotting and was compared with the corresponding EV control cells. Subsequently these data were associated with the aggressiveness of cell growth and proliferation rate. In both cell lines, overexpression of PS was 

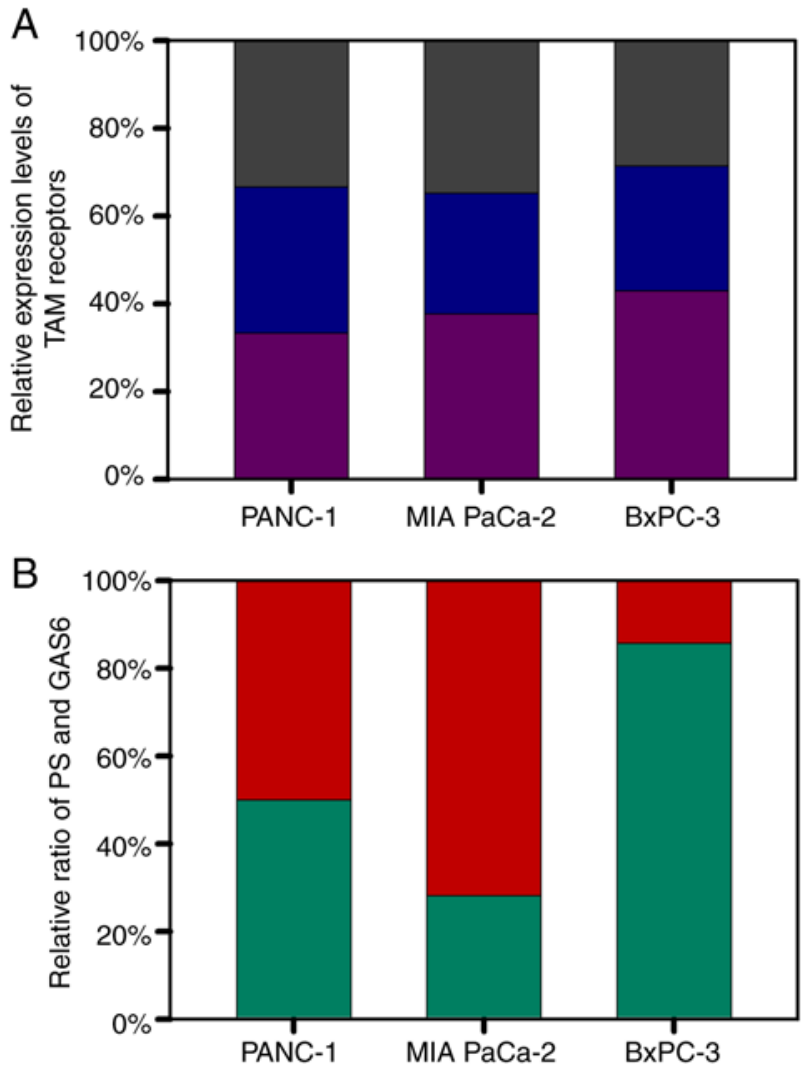

Figure 1. Relative base level expression of TAM receptors and ligands PS and GAS6 in PANC-1, MIA PaCa-2 and BXPC-3 cell lines. (A) Relative expression of individual TAM receptors [Axl (purple), Mer (blue), and Tyro3 (grey)]. (B) Relative ratio of PS (green) to the levels of GAS6 (red). PS, protein S; GAS6, growth arrest specific 6.

associated with increased expression of the apoptotic marker phospho-p53 and decreased expression of the survival marker HSP27 (25 and 15\% reduction in immunoblot band intensities for PANC-1 and MIA PaCa-2 cells, respectively; Fig. 2A). PS overexpression increased apoptosis (Fig. 2D) and caused a decrease in the survival of both cell lines, as assessed by the MTT assay (Fig. 2B). PS-overexpressing PANC-1 and MIA PaCa-2 cells exhibited 0.5 -fold and 0.8 -fold reductions in cell survival on Day 5 compared with the corresponding EV control cells (relative absorbance of the EV control was normalized to 1 and the data is not presented in the figure). PANC-1 cells exhibited a 0.9 -fold reduction in cell survival on day 1; however, MIA PaCa-2 cells did not exhibit any decrease but a significant increase in the number of cells on day 1. For both cell lines, this further resulted in a decreased number of colonies being formed during a 14-day period, compared with the EV control cells (Fig. 2C); PS overexpression had no significant effect on endogenous Gas6 expression (data not shown). The difference in aggressiveness in the growth rates of PANC-1 and MIA PaCa-2 was clearly evident. MIA PaCa-2 cells formed 808/438 (EV control/PS-overexpressing) colonies compared with 492/251 (EV control/PS-overexpressing) colonies for PANC-1 cells. The data are an average of the number of colonies calculated from three independent experiments.

To further confirm that PS overexpression caused an increase in apoptosis of pancreatic cells, flow cytometric data was generated using Annexin V/7-Aminoactinomycin D
(7AAD) staining. Despite the considerable difference in the aggressiveness in growth between the two cell lines, PS overexpression resulted in increased Annexin binding for both cell lines. For example, $82 \pm 0.43 \%$ control PANC-1 cells were double negative for Annexin $\mathrm{V}$ and $7 \mathrm{AAD}, 13 \pm 0.37 \%$ were Annexin V-positive, $1.28 \pm 0.06 \%$ were 7AAD positive, and $3.06 \pm 0.32$ were double positive. PANC1 cells that overexpressed PS were 77.33 \pm 0.47 double negative, $18 \pm 0.53 \%$ Annexin V-positive, $1.24 \pm 0.167 \mathrm{AAD}$-positive, and $3.34 \pm 0.11 \%$ double positive (Fig. 2D). Conversely, MIA $\mathrm{PaCa}-2$ cells transfected with control vector were $84.4 \pm 0.4 \%$ double negative, $12.3 \pm 0.67 \%$ Annexin V-positive, $0.8 \pm 0.17 \%$ 7AAD-positive, and $2.3 \pm 0.25 \%$ double positive. MIA PaCa-2 cells overexpressing PS were $72.79 \pm 1.48 \%$ double negative, $23.35 \pm 1.3 \%$ Annexin V-positive, $0.57 \pm 0.13 \%$ 7AAD-positive, and $3.2 \pm 0.33 \%$ double positive. Therefore, the flow cytometric data (Fig. 2D) revealed that overexpression of PS in PANC-1 increased the apoptotic population of cells by 5\%, whereas overexpression of PS in MIA PaCa-2 cells increased the apoptotic population by $13 \%$. The difference in the effect of PS overexpression in PANC-1 compared to MIA PaCa-2 may be attributed to the difference in the basal level of endogenous PS in the cells.

GAS6 overexpression enhances the survival and proliferation of PANC-1 and MIA PaCa-2 cells. GAS6 has been reported to promote prostate cancer cell survival by inhibition of apoptotic pathways (36). It was investigated whether this phenomenon occurred in pancreatic cancer cells. The comparative analysis of molecular markers revealed that stable overexpression of GAS6 was associated with reduced signaling in apoptotic phosphorylated (p)-p53 marker and enhanced survival signaling in HSP27 compared with the EV control cells (Fig. 3A). The direct effect of GAS6-mediated apoptotic inhibition was pronounced in PANC-1 cells, in which GAS6 overexpression caused 2 .7-fold increase in relative MTT assay absorbance on Day 5 compared with the EV control cells (relative absorbance of the EV control was normalized to 1 and the data is not presented in the figure), whereas in MIA PaCa-2 cells, the increase was $\sim 1.7$-fold (Fig. 3B). Furthermore, the number of colonies formed by both cell types was higher in GAS6-overexpressing cells compared with the EV control cells (Fig. 3C). MIA PaCa-2 cells formed 689/977 (EV control/GAS6-overexpressing) colonies compared with 249/563 (EV control/GAS6-overexpressing) colonies for the PANC-1 cells. Exogenous overexpression of Gas6 had no significant effect on the endogenous PS level (data not shown).

GAS6 knockdown reduces the survival and proliferation of PANC-1 and MIA PaCa-2 cells. Since GAS6 overexpression was associated with increased survival, it was anticipated that knockdown of GAS6 would reduce growth and proliferation (37). This was confirmed from the expression profiles of the apoptotic/survival markers, in which p-p53 levels were reduced in GAS6-knockdown clones compared with the EV control clones (Fig. 4A). The reduced HSP27 signal in the knockdown clones indicated an induction in apoptosis over survival, which, consequently, resulted in a decrease in the relative change of MTT assay absorbance on Day 5 in PANC-1 and MIA PaCa-2 cells compared with the EV control cells 

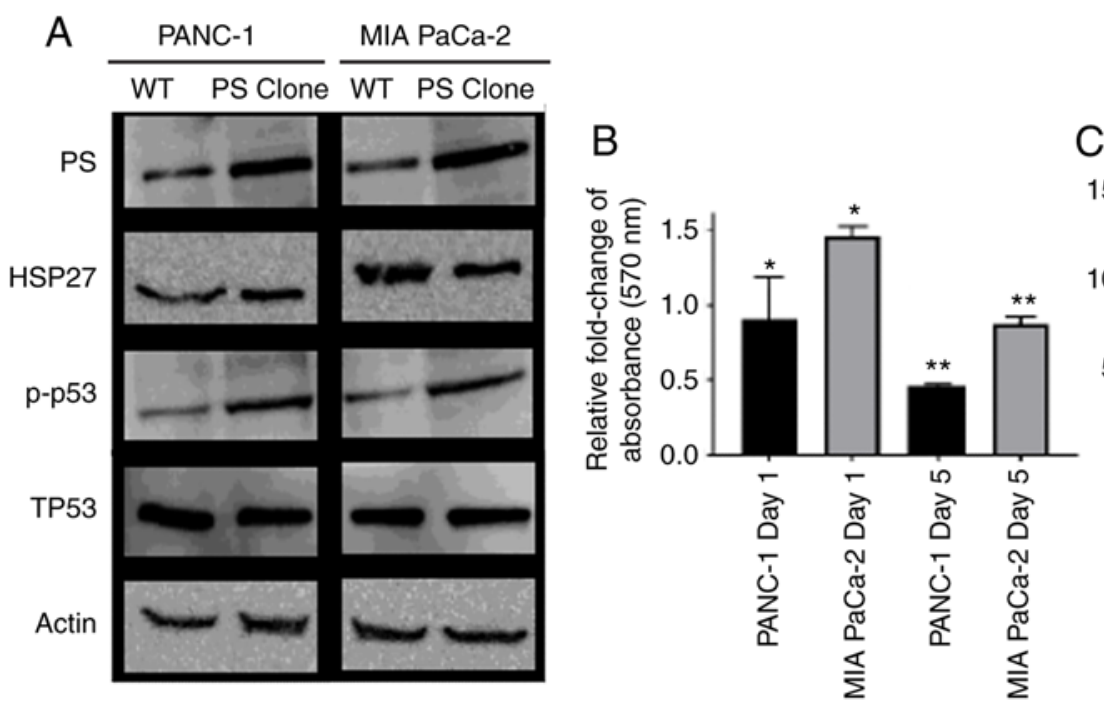

C

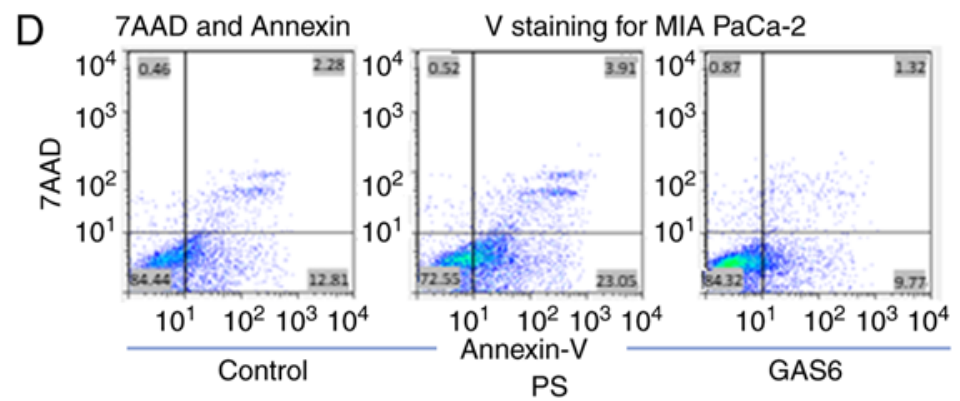

7AAD and Annexin

V staining for PANC-1

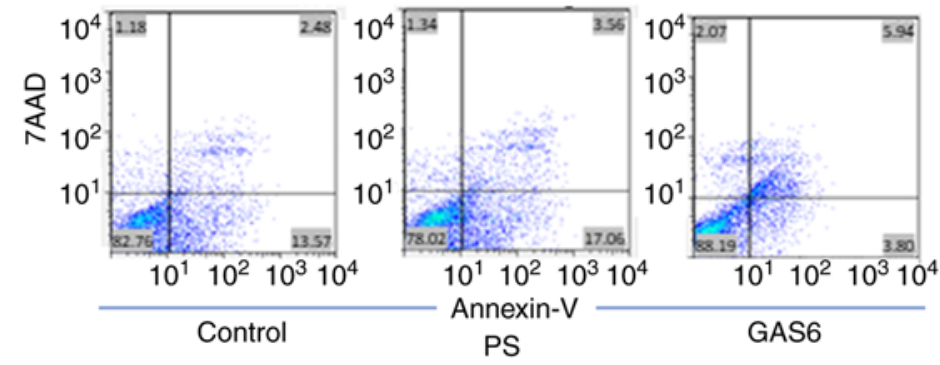

Figure 2. Induction of apoptosis to decrease survival by PS overexpression in PANC-1 and MIA PaCa-2 cells. (A) Immunoblot revealing the effect of PS overexpression on pro-apoptotic (p-p53), Total p53 (TP53) and survival (HSP27) markers. (B) Relative fold change of absorbance assessed with respect to EV control cells at $570 \mathrm{~nm}$ as a result of PS overexpression in PANC-1 (black) and MIA PaCa-2 (grey) (relative absorbance of the EV control was normalized to 1 and the data is not presented in the figure). (C) Comparison of the number of colonies formed between EV control cells and PS-overexpression clones of PANC-1 (black) and MIA PaCa-2 (grey). (D) Upper panel is the comparison of Annexin V/7-AAD staining in the vector control vs. PS-overexpressing MIA $\mathrm{PaCa}-2$ cells. Lower panel demonstrating Annexin V/7-AAD staining in the vector control vs. PS-overexpressing PANC-1 cells. Each experiment was repeated three times and the statistical significance is denoted by ${ }^{*} \mathrm{P}<0.05$ and ${ }^{* *} \mathrm{P}<0.01$. PS, protein $\mathrm{S}$; GAS6, growth arrest specific 6.

(relative absorbance of the EV control was normalized to 1 and the data is not presented in the figure) (Fig. 4B). Colony formation assays revealed a consistent, significantly higher number of colonies, 337 of PANC-1 EV control cells compared with their respective GAS6-knockdown clones, which produced 170 colonies (Fig. 4C). Conversely, MIA PaCa-2 cells produced an average of 661 colonies for EV control clones compared with 291 colonies for the GAS6-knockdown clones.

PS overexpression produces effects similar to the Mer-inhibitor UNC2025 in PANCl and MIA PaCa-2 cells. PS is an important ligand for MER in vivo; Mer overexpression in cancerous cells has been revealed to activate survival and proliferative signaling pathways $(38,39)$. Consequently, Mer is a significant target for therapeutic manipulation. A Mer-specific small molecule inhibitor, UNC2025, was used as a potential agent for treatment of glioblastoma $(40,41)$. To determine whether UNC2025 initiated an apoptotic response, a dose-dependent assay using UNC2025 was performed and it was observed that $75 \mathrm{nM}$ was an optimal concentration (data not shown). Therefore, $75 \mathrm{nM}$ was applied to PANC-1 and MIA PaCa-2 EV control cells. An MTT assay revealed a marked reduction in cell survival for the drug-treated cells (Fig. 5A). The differences in relative fold change of absorbance for PANC-1 and MIA PaCa-2 cells subjected to drug treatment compared with cells that received vehicle control were $\sim 0.3$-fold and $\sim 0.5$-fold, respectively, during the five days of treatment. However, this assay did not distinguish whether apoptosis following 
B

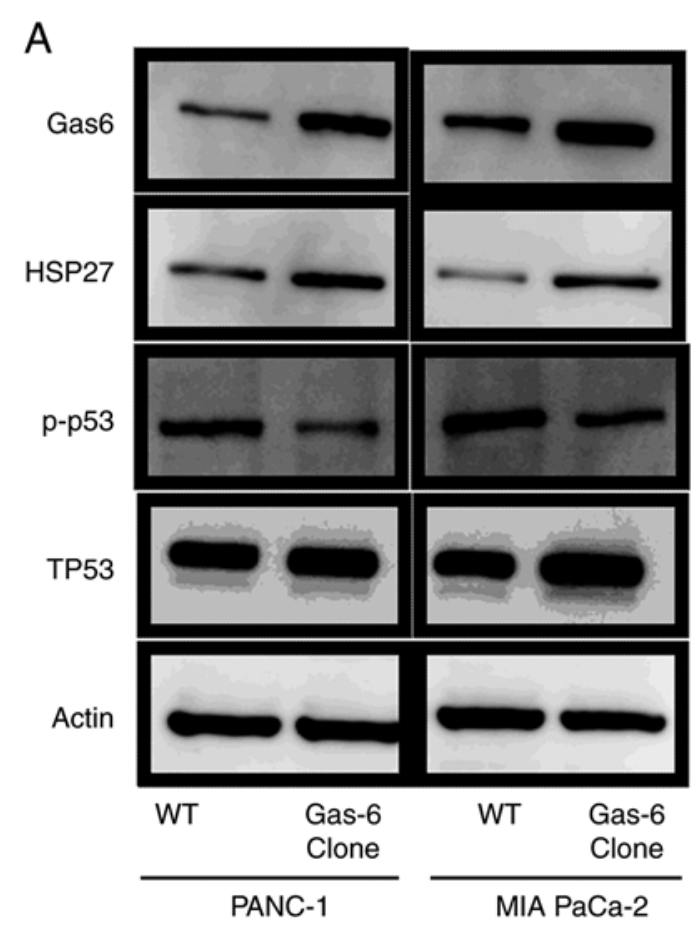

PANC-1- Black

Mia PaCa-2- Grey
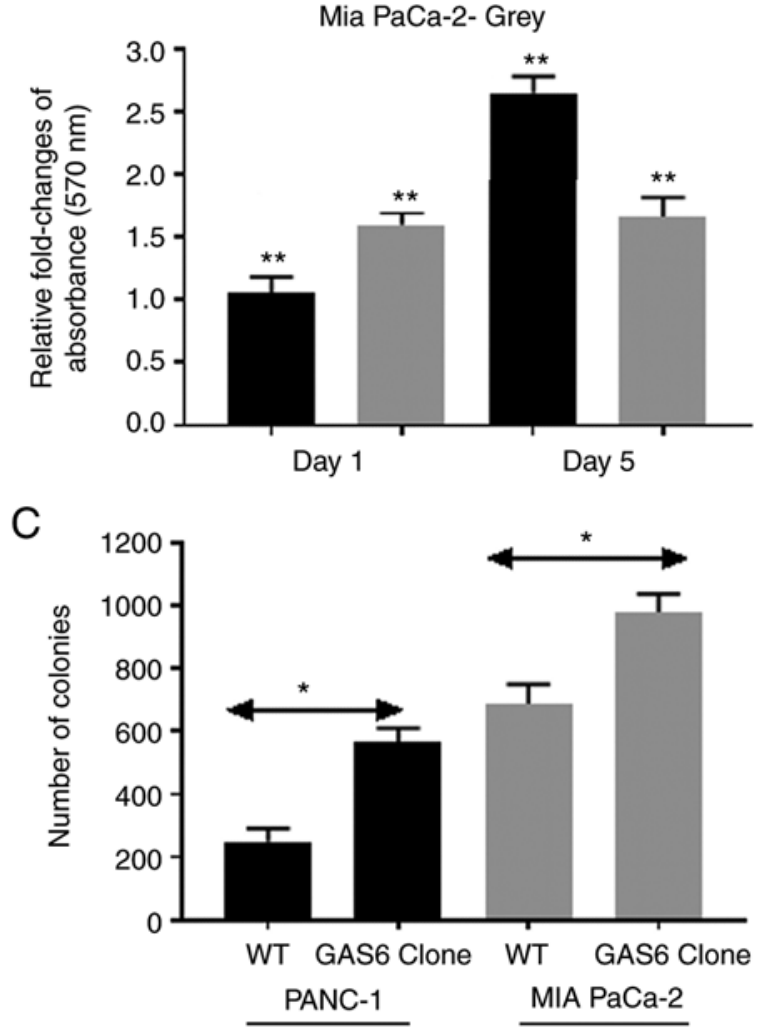

Figure 3. Decrease of apoptosis to enhance survival by GAS6 overexpression in PANC-1 and MIA PaCa-2 cells. (A) Immunoblot revealing the effect of GAS6 overexpression on pro-apoptotic (p-p53), Total p53 (TP53) and survival (HSP27) markers. (B) Relative fold change of absorbance measured with respect to EV control cells at $570 \mathrm{~nm}$ as a result of GAS6 overexpression in PANC-1 (black) and MIA PaCa-2 (grey) cells (relative absorbance of the EV control was normalized to 1 and the data is not presented in the figure). (C) Comparison of the number of colonies formed between EV control clones and GAS6-overexpression clones of PANC-1 (black) and MIA PaCa-2 (grey) cells. Each experiment was repeated three times and the statistical significance is indicated by *P $<0.05$ and ${ }^{* *} \mathrm{P}<0.01$. GAS6, growth arrest specific 6; PS, protein $\mathrm{S}$.

inhibition of Mer receptor signaling was due to the absence of interaction by either GAS6, PS, or both $(12,16)$. Thus, once the anti-proliferative effect of the drug was established, the effect of drug-induced apoptotic signaling and the natural apoptosis signaling initiated by PS overexpression in the pancreatic cancer cell lines was compared. A 0.69 -fold relative change of absorbance was observed following UNC2025 treatment in PANC-1 GAS6-knockdown cells (Fig. 5B). This change was comparable to the PANC-1 PS overexpression clones that exhibited a 0.67 -fold relative change of absorbance following treatment with the vehicle control. Further treatment with UNC2025 further decreased this change to 0.56-fold in the PS-overexpressing clones. MIA PaCa-2 GAS6-knockdown cells exhibited a milder, 0.59 -fold relative change of absorbance following UNC2025 treatment compared with the MIA PaCa-2 PS overexpression clones that exhibited 0.64-fold relative change of absorbance when treated with the vehicle (Fig. 5C). However, the 0.65-fold relative change of absorbance following UNC2025 treatment of MIA PaCa-2 EV control cells was exactly the same as that of PS-overexpressing clones under vehicle treatment, with UNC2025 further decreasing the change to 0.49 -fold.

A colony formation assay was used to assess the long-term efficacy of this PS-mediated decrease of cell proliferation. PS-overexpressing PANC-1 and MIA PaCa-2 cells were plated alongside the corresponding EV control cells and
GAS6-overexpressing cells, each receiving either $75 \mathrm{nM}$ UNC2025 or vehicle control. PS overexpression clones without drug treatment had decreased cell proliferation and colony formation to extents comparable to those of EV control cells and GAS6-overexpressing clones treated with the drug (Fig. 5D). These results provided conclusive evidence that PS overexpression achieves the same effect as that of the Mer-inhibitory drug UNC2025 in arresting cell proliferation. As elucidated in Fig. 6, it was confirmed that the PS/GAS6 ratio is crucial in terms of TAM receptor signaling, and a change in this ratio can drive cancer cells toward proliferation (GAS6 overexpression) or growth arrest (PS overexpression/GAS6 knockdown).

\section{Discussion}

PS is a natural anticoagulant, whose plasma concentration is reportedly reduced during the progression of PDAC (23). However, its properties as a signaling molecule in the context of cancer progression and cellular aggressiveness have not been studied in-depth. In the present study, two PDAC cell lines with variable degrees of aggressiveness in growth were used. The expression levels of the individual TAM receptors exhibited less than 1-fold variation between the cell lines, whereas PS and GAS6 levels were significantly different. With the PS and GAS6 levels of the moderately aggressive 
A

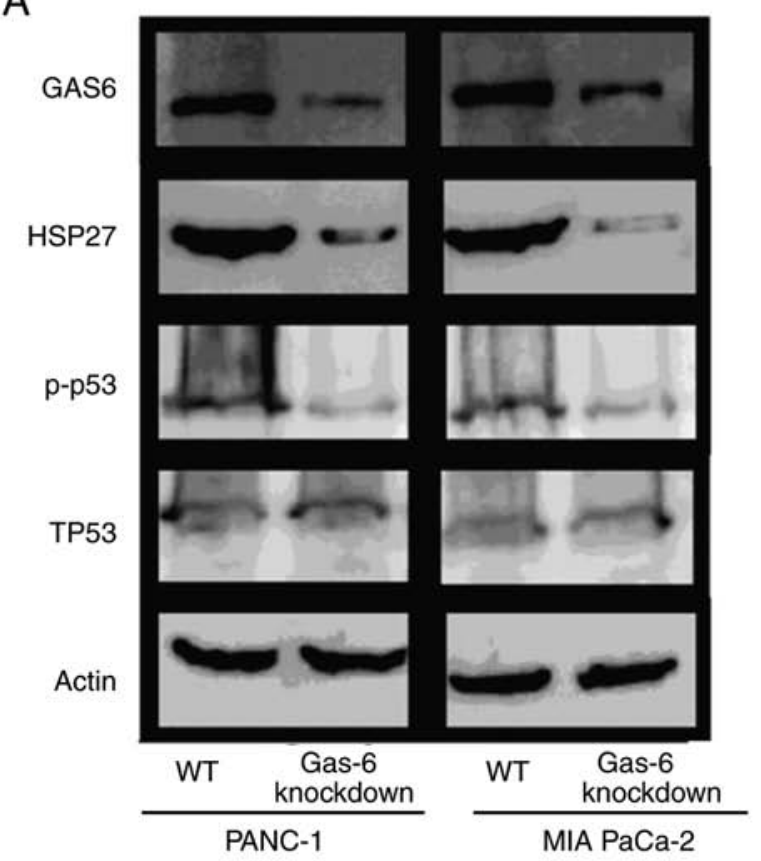

B

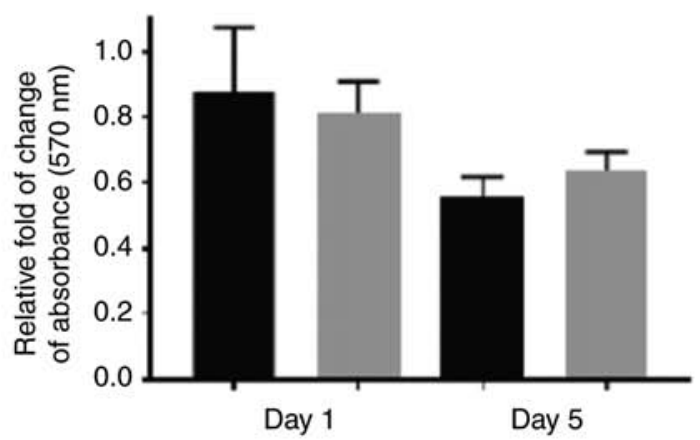

C

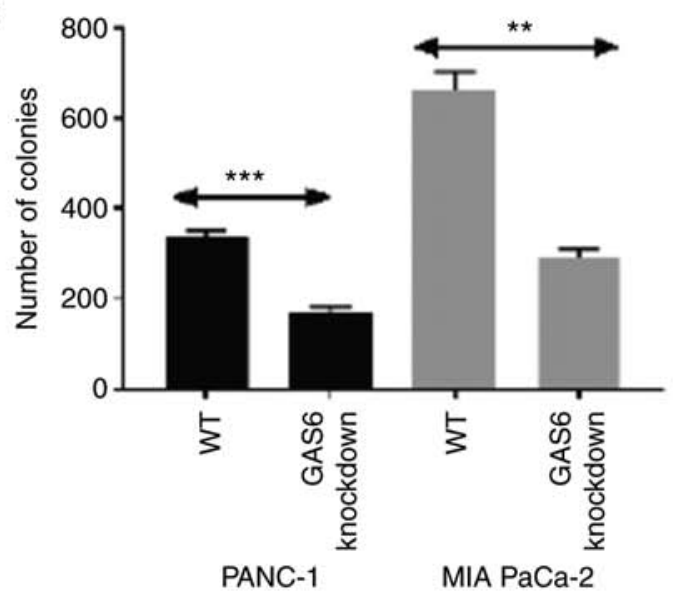

Figure 4. Induction of apoptosis to decrease survival mediated by GAS6-knockdown in PANC-1 and MIA PaCa-2 cells. (A) Immunoblot revealing the effect of GAS6-knockdown on pro-apoptotic (p-p53), Total P53 (TP53) and survival (HSP27) markers. (B) Relative fold change of absorbance measured with respect to EV control cells at $570 \mathrm{~nm}$ as a result of GAS6 knockdown in PANC-1 (black) and MIA PaCa-2 (grey) cells (relative absorbance of the EV control was normalized to 1 and the data is not presented in the figure). (C) Comparison of the number of colonies formed between the EV control and GAS6-knockdown clones of PANC-1 (black) and MIA PaCa-2 (grey) cells. Each experiment was repeated three times and the statistical significance is indicated by ${ }^{* *} \mathrm{P}<0.01$ and ${ }^{* * * *} \mathrm{P}<0.001$. GAS6, growth arrest specific 6 .

cell line PANC-1 as a baseline, a higher GAS6 level was associated with the highly aggressive cell line MIA PaCa-2, whereas significantly higher PS levels were exhibited by the least aggressive BxPC-3 cell line. To associate PS and GAS6 signaling to a specific phenotype in the proliferative potential of cells, overexpression studies on PANC-1 and MIA-PaCa-2 cells were performed. Immunoblot analysis further revealed enhanced expression of the apoptotic marker p-p53 and reduced expression of the survival marker protein HSP27. Using MTT and colony formation assays, both the short-term and the long-term pro-apoptotic effects of PS overexpression were confirmed. These assays confirmed that PS and GAS6 play vital roles in regulating the aggressiveness of pancreatic cancer cell lines; however, the present study has a limitation in elucidating the roles of PS and GAS- 6 in the motility of PANC-1 and MIA-PaCa-2. In general, aggressiveness of a cell line is assessed by invasion and migration assays; however, aggressiveness is also described in terms of cell doubling time and thereby, we did not perform invasion or migration assays. We studied the ability of the cell doubling time by colony formation assay.

GAS6 overexpression was achieved by lentiviral transduction using a LeGo-iG2-Puro plasmid containing the GAS6 gene. Overexpression of PS increased Annexin V binding compared with the basal Annexin $\mathrm{V}$ of control cells. Similar results were observed for MIA PaCa-2 cells.
PS overexpression increased Annexin V staining compared with cells carrying the control vector. Once verified, PANC-1 and MIA PaCa-2 cells overexpressing GAS6 were subjected to the same assays. The upregulation of survival protein HSP27 was associated with an increased relative fold change of absorbance as assessed by MTT assay, and the increased cell number exhibited a proliferative phenotype caused by GAS6 overexpression. GAS6 knockdown produced the opposite effect and the trend was pro-apoptotic, similar to the effect of PS-overexpression. Both plasmids (GAS6 overexpression/knockdown) have been used successfully for lentivirus-mediated transduction, and the methods were adhered to without any modification (42). By blocking the Mer receptor, the drug UNC2025 effectively inhibited any downstream signaling that results from GAS6-Mer and PS-Mer interaction. The present MTT results revealed a growth inhibitory effect of UNC2025 on PANC-1 and MIA PaCa- 2 cells. The efficacy of the PS-overexpression, however, was comparable to the drug action. Thus, the present study confirmed that overexpression of PS from a plasmid effectively decreased aggressiveness of tumor cells, a phenomenon that could be exploited to circumvent the side effects of drug-mediated blocking of TAM receptors.

Globally, cancer-associated thrombosis (CAT) is a significant risk factor in cancer treatment and therapy, but little is known about its mechanistic basis (43-45). Iodice et al 

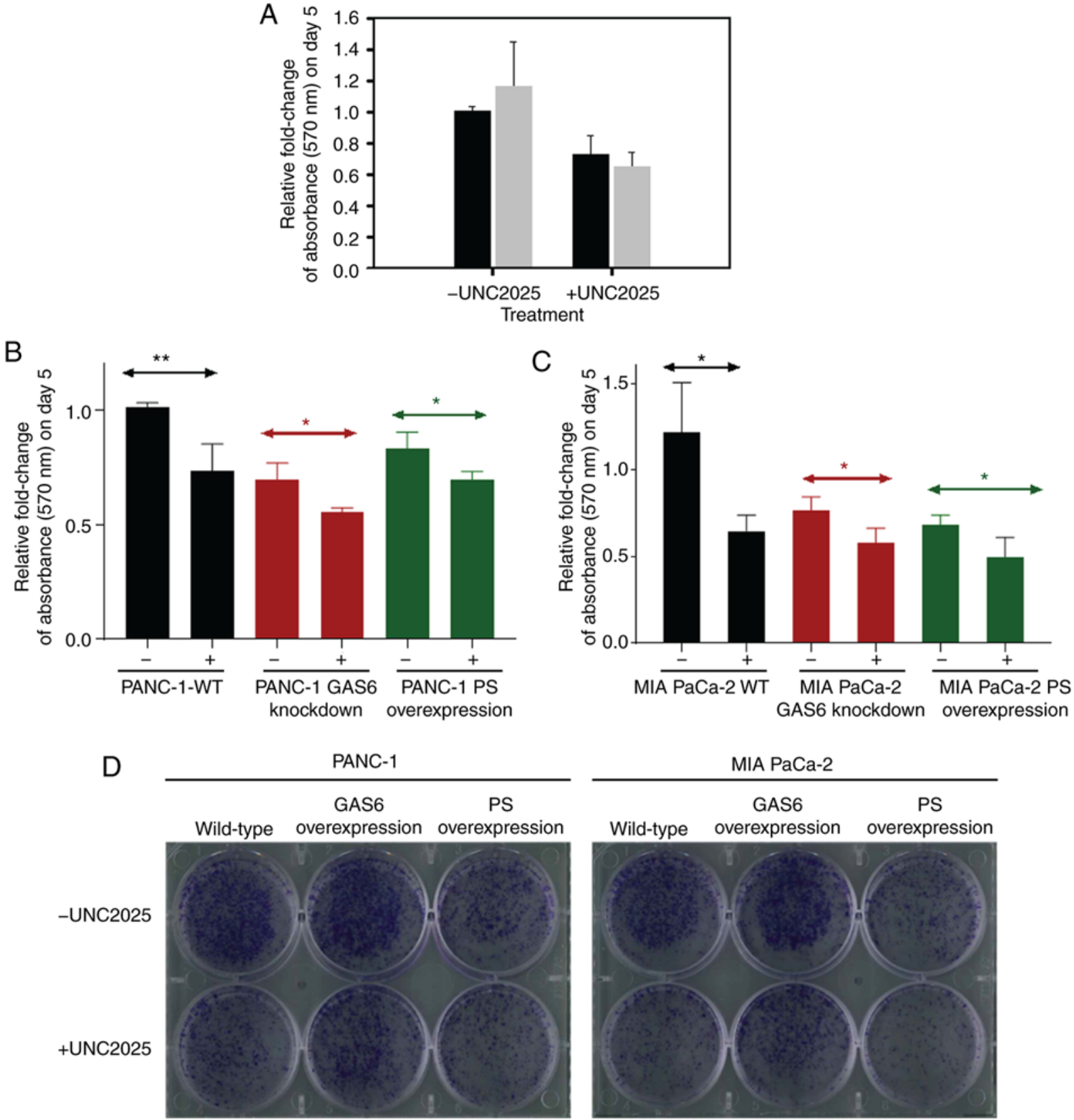

Figure 5. Comparison of PS-overexpression against UNC2025 treatment in PANC-1 and MIA PaCa-2 cells. (A) The effect of UNC2025 treatment (75 nM) on the relative fold change of absorbance measured at $570 \mathrm{~nm}$ on day 5 performed on PANC-1 (black) and MIA PaCa-2 (grey) EV control cells. (B) Comparison of the relative fold change of absorbance measured at $570 \mathrm{~nm}$ on day 5 as a result of UNC2025 treatment performed on PANC- 1 cell types (EV control, GAS6-knockdown clone and PS-overexpression clone). (C) Comparison of the relative fold change of absorbance measured at $570 \mathrm{~nm}$ on day 5 as a result of UNC2025 treatment performed on MIA PaCa-2 cell types (EV control, GAS6-knockdown clone and PS-overexpression clone). (D) Comparison of colonies of cells formed as a result of UNC2025 treatment performed on EV control clones, GAS6-knockdown clones and PS-overexpression clones of PANC-1 and MIA PaCa- 2 cells. Each experiment was repeated three times and the statistical significance is indicated by " $\mathrm{P}<0.05$ and ${ }^{* *} \mathrm{P}<0.01$. PS, protein $\mathrm{S}$; GAS6, growth arrest specific 6 .

examined a number of population studies and inferred that patients with VTE have a six-fold higher risk of developing pancreatic cancer than the general population (46). As reviewed by Sohail and Saif, multiple events can result in hypercoagulability in pancreatic cancer (47). Such events include retroperitoneal location of tumors, tumor specific increase in procoagulant factors (tissue factor, thrombin and fibrin), and decreases in anticoagulants such as APC, TFPI, and PS. Initially identified as a cofactor of APC $(48,49)$, PS was later found to mediate an APC-independent anticoagulant function as a cofactor of TFPI $(2,50)$. Recently, we demonstrated a more direct function of PS in the coagulation cascade, whereby PS directly binds to activated Factor IX in an APC-independent manner and inhibits the formation of the intrinsic tenase complex required for thrombus formation $(51,52)$. Incidentally, patients with heterozygous PS-deficiency exhibited an increased risk of VTE (53). An initial screening of the players in the coagulation pathway revealed an interesting participant in PS, a well-known anticoagulant with diverse functions, including serving as a signaling molecule $(7,43)$. 

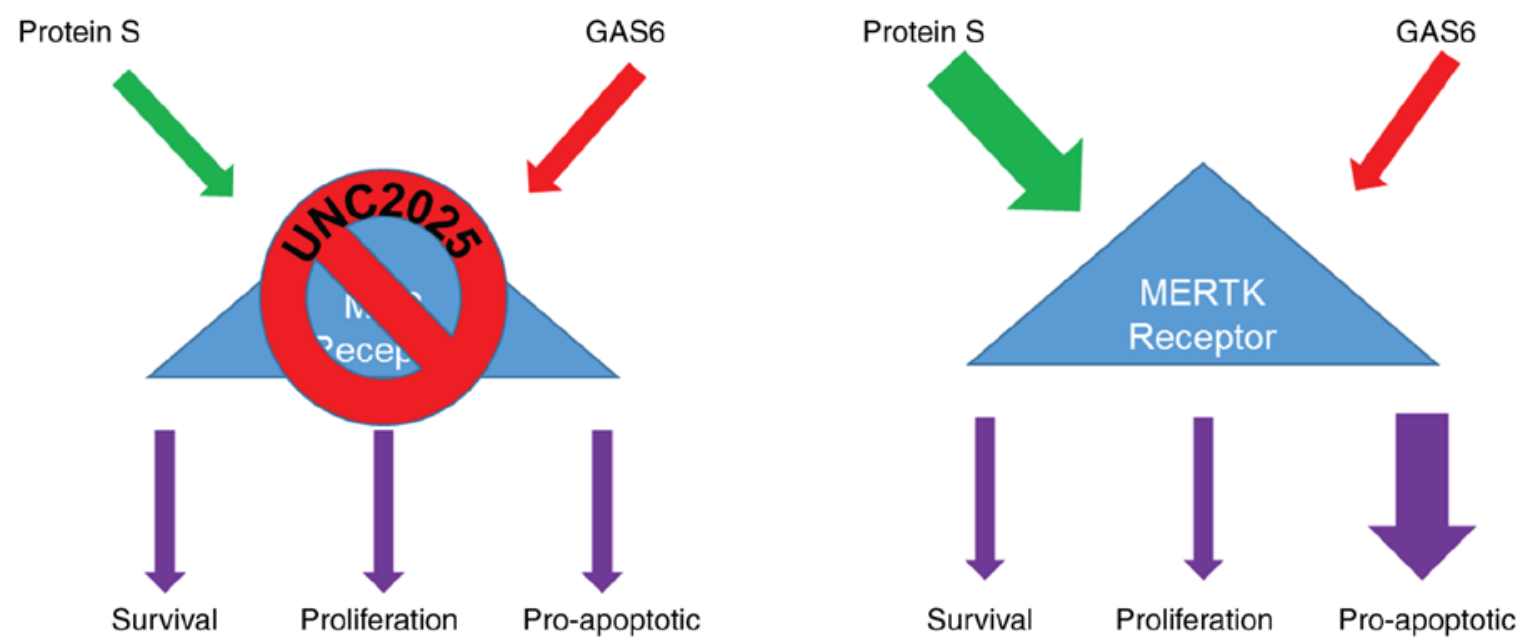

Figure 6. Schematic revealing that PS-overexpression favors the apoptotic phenotype, the long-term benefits of which can potentially surpass the side-effects of TAM-targeting drugs. PS, protein S; GAS6, growth arrest specific 6.

PS and GAS6 are TAM receptor family ligands $(54,55)$, with variable affinities for the individual receptors (56). The expression levels of the TAM receptors vary across cell and tissue type and are generally upregulated in tumors (57). As a result, the downstream effects of TAM signaling, such as proliferation, efferocytosis, and anti-inflammatory activity, become dysregulated (39,58-60). The overexpression of GAS6 and Axl has been reported in pancreatic cancer, both in vitro and in vivo (61-63). Shen et al have extensively elucidated the scope of targeting TAM receptors for designing drugs intended to inhibit cancer progression (64). They reported that, despite considerable effort, application of TAM-inhibitory drugs has had minimal success. The pathological complexity of cancer and the global output of TAM-dependent signaling pathways are significant obstacles for use of these drugs because they cause severe side effects and are associated with drug resistance. A screening of the common anticoagulants during the progression of PDAC in a group of patients revealed an increase in the plasma level of TFPI, whereas the level of free PS exhibited a statistically significant decrease (23). A similar association of decreased PS and increased GAS6 levels has been reported in patients with systemic lupus erythromatosus, resulting in widespread autoimmune disorders mediated by an imbalance in TAM signaling $(65,66)$.

The main goal of the present study was to demonstrate that overexpressing PS could be a strategy for reducing aggressiveness of PDAC without targeting essential TAM receptor signaling pathways. Thrombotic complications and hypercoagulopathies are commonly associated with the progression of PDAC. The amount of PS, a known anticoagulant, has been reported to decrease in patients during the progression of PDAC, possibly contributing to the hypercoagulopathies. PS has also been identified as an important signaling molecule that binds a family of tyrosine kinase receptors known as TAM receptors, thereby triggering multiple downstream functions, such as cell survival, proliferation, efferocytosis, and apoptosis. However, the properties of PS as a signaling molecule in the context of cancer progression and cellular aggressiveness have not been studied adequately. In the present study, it was demonstrated that PS-TAM interaction produced a pro-apoptotic effect, whereas GAS6-mediated TAM signaling promoted proliferation and survival in select PDAC cell lines. Both long-term and short-term effects of natural PS overexpression were comparable with treatment of the cell lines with UNC2025, a drug that inhibits the Mer-receptor. We intend to study the thrombotic effects of PS in pancreatic cancer in the near future.

The physiological importance of the present study lies in the fact that a drug action was emulated by overexpressing PS, a natural protein that is already reduced in pancreatic cancer and whose deficiency is strongly associated with the severe thrombotic complications that are synchronous with PDAC progression. The present study can provide the basis for developing newer strategies of PDAC treatment and concurrently improving the quality of life of patients with cancer-associated thrombosis.

\section{Acknowledgements}

Not applicable.

\section{Funding}

The present study was supported by the Louisiana State University Health Sciences Center Special Appropriation Award (0101500039) and the National Heart, Lung, and Blood Institute, National Institutes of Health grant no. 5R01HL118557-02.

\section{Availability of data and materials}

The datasets used during the present study are available from the corresponding author upon reasonable request.

\section{Authors' contributions}

VSP performed the experiments, analyzed the data, and assisted in revising the manuscript by collecting new data. ADa performed the experiments, analyzed the data, and 
wrote the initial version of the manuscript. ADo maintained the cells, analyzed the data, and reviewed the manuscript. BL collected flow cytometric data and provided resources for the flow cytometric assessment. RM designed the study, performed the statistical analysis, and reviewed and edited the final manuscript. All authors read and approved the final manuscript and agree to be accountable for all aspects of the research in ensuring that the accuracy and integrity of any part of the work are appropriately investigated and resolved.

\section{Ethics approval and consent to participate}

Not applicable.

\section{Patient consent for publication}

Not applicable.

\section{Competing interests}

The authors declare that they no competing interests.

\section{References}

1. Arnljots B and Dahlbäck B: Protein S as an in vivo cofactor to activated protein $\mathrm{C}$ in prevention of microarterial thrombosis in rabbits. J Clin Invest 95: 1987-1993, 1995.

2. Hackeng TM, Seré KM, Tans G and Rosing J: Protein S stimulates inhibition of the tissue factor pathway by tissue factor pathway inhibitor. Proc Natl Acad Sci USA 103: 3106-3111, 2006.

3. Rosing J, Maurissen LF, Tchaikovski SN, Tans G and Hackeng TM: Protein S is a cofactor for tissue factor pathway inhibitor. Thromb Res 122 (Suppl 1): S60-S63, 2008.

4. Suleiman L, Négrier C and Boukerche H: Protein S: A multifunctional anticoagulant vitamin K-dependent protein at the crossroads of coagulation, inflammation, angiogenesis, and cancer. Crit Rev Oncol Hematol 88: 637-654, 2013.

5. Lemke G: Biology of the TAM receptors. Cold Spring Harb Perspect Biol 5: a009076, 2013.

6. Lemke $\mathrm{G}$ and Rothlin CV: Immunobiology of the TAM receptors. Nat Rev Immunol 8: 327-336, 2008.

7. Anderson HA, Maylock CA, Williams JA, Paweletz CP, Shu H and Shacter E: Serum-derived protein S binds to phosphatidylserine and stimulates the phagocytosis of apoptotic cells. Nat Immunol 4: 87-91, 2003.

8. Burstyn-Cohen T: TAM receptor signaling in development. Int J Dev Biol 61: 215-224, 2017.

9. Burstyn-Cohen T, Heeb MJ and Lemke G: Lack of protein S in mice causes embryonic lethal coagulopathy and vascular dysgenesis. J Clin Invest 119: 2942-2953, 2009.

10. Fraineau S, Monvoisin A, Clarhaut J, Talbot J, Simonneau C, Kanthou C, Kanse SM, Philippe M and Benzakour O: The vitamin K-dependent anticoagulant factor, protein S, inhibits multiple VEGF-A-induced angiogenesis events in a Mer- and SHP2-dependent manner. Blood 120: 5073-5083, 2012.

11. Schneider C, King RM and Philipson L: Genes specifically expressed at growth arrest of mammalian cells. Cell 54: 787-793, 1988.

12. Nagata K, Ohashi K, Nakano T, Arita H, Zong C, Hanafusa H and Mizuno K: Identification of the product of growth Arrest-specific Gene 6 as a common ligand for Axl, Sky, and mer receptor tyrosine kinases. J Biol Chem 271: 30022-30027, 1996.

13. Mark MR, Chen J, Hammonds RG, Sadick M and Godowsk PJ: Characterization of Gas6, a member of the superfamily of $G$ domain-containing proteins, as a ligand for rse and Axl. J Biol Chem 271: 9785-9789, 1996.

14. van der Meer JH, van der Poll T and van 't Veer C: TAM receptors, Gas6, and protein S: Roles in inflammation and hemostasis. Blood 123: 2460-2469, 2014

15. Zagórska A, Través PG, Lew ED, Dransfield I and Lemke G: Diversification of TAM receptor tyrosine kinase function. Nat Immunol 15: 920-928, 2014.
16. Dransfield I and Farnworth S: Axl and mer receptor tyrosine kinases: Distinct and nonoverlapping roles in inflammation and cancer? Adv Exp Med Biol 930: 113-132, 2016.

17. Bosurgi L, Bernink JH, Delgado Cuevas V, Gagliani N, Joannas L, Schmid ET, Booth CJ, Ghosh S and Rothlin CV: Paradoxical role of the proto-oncogene Axl and Mer receptor tyrosine kinases in colon cancer. Proc Natl Acad Sci USA 110: 13091-13096, 2013.

18. Siegel RL, Miller KD and Jemal A: Cancer statistics, 2017. CA Cancer J Clin 67: 7-30, 2017.

19. Bilimoria KY, Bentrem DJ, Ko CY, Stewart AK, Winchester DP and Talamonti MS: National failure to operate on early stage pancreatic cancer. Ann Surg 246: 173-180, 2007.

20. Cronin-Fenton DP, Søndergaard F, Pedersen LA, Fryzek JP, Cetin K, Acquavella J, Baron JA and Sørensen HT: Hospitalisation for venous thromboembolism in cancer patients and the general population: a population-based cohort study in Denmark, 1997-2006. Br J Cancer 103: 947-953, 2010.

21. Walker AJ, Card TR, West J, Crooks C and Grainge MJ: Incidence of venous thromboembolism in patients with cancer-a cohort study using linked United Kingdom databases. Eur J Cancer 49: 1404-1413, 2013.

22. Horsted F, West $\mathbf{J}$ and Grainge MJ: Risk of venous thromboembolism in patients with cancer: A systematic review and meta-analysis. PLoS Med 9: e1001275, 2012.

23. Lindahl AK, Odegaard OR, Sandset PM and Harbitz TB: Coagulation inhibition and activation in pancreatic cancer. Changes during progress of disease. Cancer 70: 2067-2072, 1992.

24. Gradiz R, Silva HC, Carvalho L, Botelho MF and Mota-Pinto A: MIA PaCa-2 and PANC-1-pancreas ductal adenocarcinoma cell lines with neuroendocrine differentiation and somatostatin receptors. Sci Rep 6: 21648, 2016.

25. Tan MH, Nowak NJ, Loor R, Ochi H, Sandberg AA, Lopez C, Pickren JW, Berjian R, Douglass HO Jr and Chu TM: Characterization of a new primary human pancreatic tumor line. Cancer Invest 4: 15-23, 1986.

26. Yunis AA, Arimura GK and Russin DJ: Human pancreatic carcinoma (MIA PaCa-2) in continuous culture: Sensitivity to asparaginase. Int J Cancer 19: 128-135, 1977.

27. Tai MH, Olson LK, Madhukar BV, Linning KD, Van Camp L, Tsao MS and Trosko JE: Characterization of gap junctional intercellular communication in immortalized human pancreatic ductal epithelial cells with stem cell characteristics. Pancreas 26: e18-e26, 2003.

28. Qian J, Niu J, Li M, Chiao PJ and Tsao MS: In vitro modeling of human pancreatic duct epithelial cell transformation defines gene expression changes induced by K-ras oncogenic activation in pancreatic carcinogenesis. Cancer Res 65: 5045-5053, 2005.

29. Rezende SM, Razzari C and Simmonds RE: In vitro high level protein $\mathrm{S}$ expression after modification of protein $\mathrm{S}$ cDNA. Thromb Haemost 90: 1214-1215, 2003.

30. Levkovitz Y and Baraban JM: A dominant negative inhibitor of the Egr family of transcription regulatory factors suppresses cerebellar granule cell apoptosis by blocking c-Jun activation. J Neurosci 21: 5893-5901, 2001.

31. Weber K, Bartsch U, Stocking C and Fehse B: A multicolor panel of novel lentiviral 'gene ontology' (LeGO) vectors for functional gene analysis. Mol Ther 16: 698-706, 2008.

32. Weber K, Mock U, Petrowitz B, Bartsch U and Fehse B: Lentiviral gene ontology (LeGO) vectors equipped with novel drug-selectable fluorescent proteins: New building blocks for cell marking and multi-gene analysis. Gene Ther 17: 511-520, 2010.

33. Livak KJ and Schmittgen TD: Analysis of relative gene expression data using real-time quantitative PCR and the 2(-Delta Delta C(T)) method. Methods 25: 402-408, 2001.

34. Feoktistova M, Geserick P and Leverkus M: Crystal violet assay for determining viability of cultured cells. Cold Spring Harb Protoc 2016: pdb.prot087379, 2016.

35. Niyazi M, Niyazi I and Belka C: Counting colonies of clonogenic assays by using densitometric software. Radiat Oncol 2: 4, 2007.

36. Lee E, Decker AM, Cackowski FC, Kana LA, Yumoto K, Jung Y, Wang J, Buttitta L, Morgan TM and Taichman RS: Growth Arrest-Specific 6 (GAS6) promotes prostate cancer survival by g1 arrest/s phase delay and inhibition of apoptosis during chemotherapy in bone marrow. J Cell Biochem 117: 2815-2824, 2016.

37. Gustafsson A, Bostrom AK, Ljungberg B, Axelson $\mathrm{H}$ and Dahlbäck B: Gas6 and the receptor tyrosine kinase Axl in clear cell renal cell carcinoma. PLoS One 4: e7575, 2009.

38. Cummings CT, Deryckere D, Earp HS and Graham DK: Molecular pathways: MERTK signaling in cancer. Clin Cancer Res 19: 5275-5280, 2013. 
39. Keating AK, Salzberg DB, Sather S, Liang X, Nickoloff S, Anwar A, Deryckere D, Hill K, Joung D, Sawczyn KK, et al: Lymphoblastic leukemia/lymphoma in mice overexpressing the Mer (MerTK) receptor tyrosine kinase. Oncogene 25: 6092-6100, 2006.

40. Sufit A, Lee-Sherick AB, DeRyckere D, Rupji M, Dwivedi B, Varella-Garcia M,Pierce AM, Kowalski J, Wang X, Frye SV, et al: MERTK inhibition induces polyploidy and promotes cell death and cellular senescence in glioblastoma multiforme. PLoS One 11: e0165107, 2016.

41. Wu J, Frady LN, Bash RE, Cohen SM, Schorzman AN, Su YT, Irvin DM, Zamboni WC, Wang X, Frye SV, et al: MerTK as a therapeutic target in glioblastoma. Neuro Oncol 20: 92-102, 2018.

42. Waizenegger JS, Ben-Batalla I, Weinhold N, Meissner T, Wroblewski M, Janning M, Riecken K, Binder M, Atanackovic D, Taipaleenmaeki H, et al: Role of Growth arrest-specific gene 6-Mer axis in multiple myeloma. Leukemia 29: 696-704, 2015.

43. Mandalà M, Falanga A and Roila F: Management of venous thromboembolism (VTE) in cancer patients: ESMO Clinical Practice Guidelines. Ann Oncol 22 (Suppl 6): vi85-vi92, 2011.

44. Hisada Y, Geddings JE, Ay C and Mackman N: Venous thrombosis and cancer: From mouse models to clinical trials. J Thromb Haemost 13: 1372-1382, 2015.

45. Sheth RA, Niekamp A, Quencer KB, Shamoun F, Knuttinen MG, Naidu S and Oklu R: Thrombosis in cancer patients: Etiology, incidence, and management. Cardiovasc Diagn Ther 7 (Suppl 3): S178-S185, 2017.

46. Iodice S, Gandini S, Löhr M, Lowenfels AB and Maisonneuve P. Venous thromboembolic events and organ-specific occult cancers: A review and meta-analysis. J Thromb Haemost 6 : 781-788, 2008

47. Sohail MA and Saif MW: Role of anticoagulation in the management of pancreatic cancer. JOP 10: 82-87, 2009.

48. Walker FJ: Regulation of activated protein $\mathrm{C}$ by a new protein. A possible function for bovine protein S. J Biol Chem 255: 5521-5524, 1980

49. Walker FJ, Chavin SI and Fay PJ: Inactivation of factor VIII by activated protein $\mathrm{C}$ and protein S. Arch Biochem Biophys 252: 322-328, 1987.

50. Ndonwi M and Broze G Jr: Protein S enhances the tissue factor pathway inhibitor inhibition of factor Xa but not its inhibition of factor VIIa-tissue factor. J Thromb Haemost 6: 1044-1046, 2008.

51. Chattopadhyay R, Sengupta T and Majumder R: Inhibition of intrinsic Xase by protein S: A novel regulatory role of protein $\mathrm{S}$ independent of activated protein C. Arterioscler Thromb Vasc Biol 32: 2387-2393, 2012.

52. Plautz WE, Sekhar Pilli VS, Cooley BC, Chattopadhyay R, Westmark PR, Getz T, Paul D, Bergmeier W, Sheehan JP and Majumder R: Anticoagulant Protein S targets the factor IXa Heparin-binding exosite to prevent thrombosis. Arterioscler Thromb Vasc Biol 38: 816-828, 2018.

53. Saller F, Brisset AC, Tchaikovski SN, Azevedo M, Chrast R, Fernández JA, Schapira M, Hackeng TM, Griffin JH and Angelillo-Scherrer A: Generation and phenotypic analysis of protein S-deficient mice. Blood 114: 2307-2314, 2009.

54. Burstyn-Cohen T, Lew ED, Traves PG, Burrola PG, Hash JC and Lemke G: Genetic dissection of TAM receptor-ligand interaction in retinal pigment epithelial cell phagocytosis. Neuron 76 $1123-1132,2012$
55. Nakamura YS, Hakeda Y, Takakura N, Kameda T, Hamaguchi I, Miyamoto T, Kakudo S, Nakano T, Kumegawa M and Suda T: Tyro 3 receptor tyrosine kinase and its ligand, gas6, stimulate the function of osteoclasts. Stem Cells 16: 229-238, 1998.

56. Hafizi S and Dahlbäck B: Gas6 and Protein S. Vitamin $\mathrm{K}$-dependent ligands for the Axl receptor tyrosine kinase subfamily. FEBS J 273: 5231-5244, 2006.

57. Linger RM, Keating AK, Earp HS and Graham DK: TAM receptor tyrosine kinases: Biologic functions, signaling, and potential therapeutic targeting in human cancer. Adv Cancer Res 100: 35-83, 2008.

58. Graham DK, Salzberg DB, Kurtzberg J, Sather S, Matsushima GK, Keating AK, Liang X, Lovell MA, Williams SA, Dawson TL, et al: Ectopic expression of the proto-oncogene mer in pediatric t-cell acute lymphoblastic leukemia. Clin Cancer Res 12: 2662-2669, 2006.

59. Shankar SL, O'Guin K, Kim M, Varnum B, Lemke G, Brosnan CF and Shafit-Zagardo B: Gas6/Axl Signaling activates the phosphatidylinositol 3-Kinase/Akt1 survival pathway to protect oligodendrocytes from tumor necrosis factor alpha-induced apoptosis. J Neurosci 26: 5638-5648, 2006.

60. Shankar SL, O'Guin K, Cammer M, McMorris FA, Stitt TN, Basch RS, Varnum B and Shafit-Zagardo B: The growth arrest-specific gene product Gas 6 promotes the survival of human oligodendrocytes via a phosphatidylinositol 3-kinase-dependent pathway. J Neurosci 23: 4208-4218, 2003.

61. Moody G, Belmontes B, Masterman S, Wang W, King C, Murawsky C, Tsuruda T, Liu S, Radinsky R and Beltran PJ: Antibody-mediated neutralization of autocrine Gas6 inhibits the growth of pancreatic ductal adenocarcinoma tumors in vivo. Int J Cancer 139: 1340-1349, 2016.

62. Song X, Wang H, Logsdon CD, Rashid A, Fleming JB, Abbruzzese JL, Gomez HF, Evans DB and Wang $\mathrm{H}$ : Overexpression of receptor tyrosine kinase Axl promotes tumor cell invasion and survival in pancreatic ductal adenocarcinoma. Cancer 117: 734-743, 2011.

63. Koorstra JB, Karikari C, Feldmann G, Bisht S, Rojas PL, Offerhaus GJ, Alvarez $\mathrm{H}$ and Maitra A: The Axl receptor tyrosine kinase confers an adverse prognostic influence in pancreatic cancer and represents a new therapeutic target. Cancer Biol Ther 8: 618-626, 2009.

64. Shen Y, Chen X, He J, Liao D and Zu X: Axl inhibitors as novel cancer therapeutic agents. Life Sci 198: 99-111, 2018.

65. Kim HA, Nam JY, Jung JY, Bae CB, An JM, Jeon JY, Kim BS and Suh CH: Serum growth arrest-specific protein 6 levels are elevated in adult-onset Still's disease. Clin Rheumatol 33: 865-868, 2014.

66. Suh CH, Hilliard B, Li S, Merrill JT and Cohen PL: TAM receptor ligands in lupus: Protein $\mathrm{S}$ but not Gas6 levels reflect disease activity in systemic lupus erythematosus. Arthritis Res Ther 12: R146-R146, 2010.

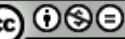

This work is licensed under a Creative Commons Attribution-NonCommercial-NoDerivatives 4.0 International (CC BY-NC-ND 4.0) License. 